Abstracted/indexed in Academic Search Complete, Asia Journals Online, Bangladesh Journals Online, Biological Abstracts, BIOSIS Previews, CAB Abstracts, Current Abstracts, Directory of Open Access Journals, EMBASE/Excerpta Medica, Global Health, Google Scholar, HINARI (WHO), International Pharmaceutical Abstracts, Open J-gate, Science Citation Index Expanded, SCOPUS and Social Sciences Citation Index;

ISSN: $1991-0088$

\title{
Association between SLCO1B3 gene polymorphism and prostate cancer risk: A meta-analytic study
}

\author{
Qunshan Shen, Yu Liang, Haibo Li, Mei Chen, Jun Zhang, Pengcheng Feng, Jie Meng and \\ Haiyun Yu
}

Department of Urology, The 105th Hospital of People's Liberation Army, Hefei 230061, China.

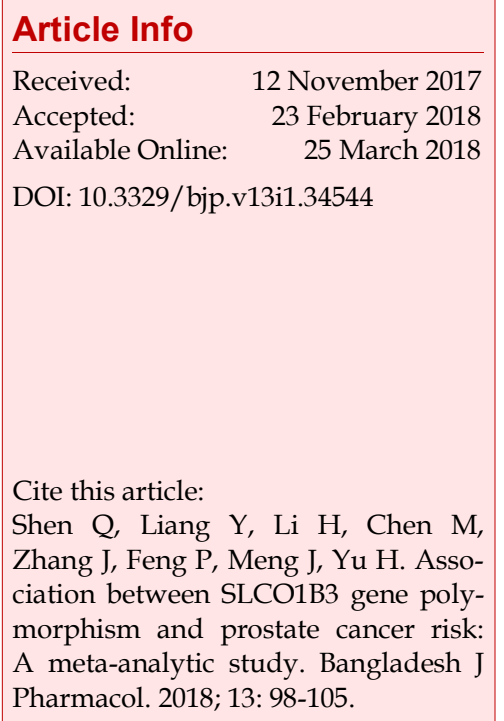

\begin{abstract}
The aim of this meta-analysis was to assess the association between SLCO1B3 gene polymorphism and prostate cancer risk. PubMed, Embase, Cochrane Library, and Web of Science from inception to September 2017 were searched. Three authors independently selected studies, extracted data and assessed risk of bias. 5 articles published from 2008 to 2013 with 840 patients were included in this meta-analysis and were from Japan, USA and China. The prostate cancer risk of SLCO1B3 (rs4149117, GG) was markedly higher than that of SLCO1B3 (rs4149117, TT/TG, RR=0.44, 95\%CI: 0.39-0.49, p<0.00001), rs4149117 (TT, RR=0.37, 95\%CI: 0.32-0.42, p<0.00001) and rs4149117 (TG, RR= $0.07,95 \% \mathrm{CI}: 0.05-0.10, \mathrm{p}<0.00001) .2$ or 5 years risk free symptoms (RFS) of prostate cancer patient with SLCO1B3 (rs4149117, GG) was markedly higher than that of SLCO1B3 (rs4149117, TT/TG) (RR=-0.17, 95\% CI: $-0.27--0.07, p=$ 0.001 and $\mathrm{RR}=-0.08,95 \% \mathrm{CI}:-0.16-0.00, \mathrm{p}=0.004)$. However, no evidence showed there existed significant statistical relationship between SLCO1B3 (rs4149117) and 10 years RFS of prostate cancer (RR= $-0.07,95 \%$ CI: $-0.19-0.06$, $\mathrm{p}=0.29$ ). These data suggest that SLCO1B3 (rs4149117, GG) enhanced the RFS of prostate cancer.
\end{abstract}

\section{Introduction}

Prostate cancer is one of the most common tumors damaging male health. Its morbidity ranks the top among the male malignancies in USA (Obara et al., 2017). It takes the second place in the cause of death in male, only second to lung cancer (Obara et al., 2017). Morbidity of prostate cancer in China is far lower than that in Western countries. However, morbidity of prostate cancer in China displays an increasing and younger trend within the past 20 years. This may be related to the lifestyle, lifetime extension, aging of population and improved diagnostic technique (Ben-Josef et al., 2017).

Prostate cancer shows no specific early symptoms. However, it frequently develops local invasion or distant metastasis at advanced stage. Pelvic lymph node is the earliest and commonest site of metastasis for the prostate cancer (Zhou et al., 2015). Patients with localized prostate cancer have the 5-year survival of almost $100 \%$ (Hieronymus et al., 2014). However, the 5year survival of prostate cancer patient with distant metastasis has decreased to $29 \%$. Prostate cancer patient has dismal prognosis in the presence of metastasis, severely affecting the quality of life (Zhou et al., 2015).

Prostate cancer frequently occurs in the elderly men, with the median age of 72 years and the peak age of 7579 years (Obara et al., 2017). At present, prostate cancer patients aged below 60 years are rare in China, but the number is remarkably increased over the age of 60 years (Petrioli et al., 2015). Risk factors inducing prostate cancer have not been determined yet. The 
known definite factors include age, race and heredity (Petrioli et al., 2015). Study targeting the risk of incidence of prostate cancer and single nucleotide polymorphism have been carried out (Zhou et al., 2015). Over 50 single nucleotide polymorphisms closely related to prostate cancer have been discovered, which are promising to be used to predict the risk of prostate cancer. Therefore, related research targeting prostate cancer is necessary (Ben-Josef et al., 2017).

Transmembrane transport plays a crucial role in drug absorption, distribution, biotransformation and excretion in the body. The physiochemical properties of drug itself, such as molecular size, hydrophilicity/lipophilicity, and charge, will affect the transmembrane transport process. In addition, membrane transport protein is also one of the important factors affecting the transmembrane transport process. ATP-binding cassette and solute carrier (SLC) superfamilies are the two major drug transporter families in the body. They are responsible for drug excretion and absorption. Of them, organic anion transporting polypeptides (Oatp in rodent and OATP in human) belong to the SLC superfamily. They are extensively distributed in gastrointestinal tract, liver, kidneys and blood-brain barrier. Moreover, they can mediate the absorption and transport of multiple endogenous substances and common clinical drugs (Ayalasomayajula et al., 2016).

Oatp1a1 is the first member of the OATP family first successfully isolated in 1994. So far, a total of 52 OATP members belonging to 8 species and 12 families have been discovered. 11 OATPs have been discovered in human body (Pei et al., 2017). Among them, OATP1B1 and OATP1B3 are specifically distributed in basal lateral membrane of liver (lateral sinusoid membrane). They are mainly responsible for transporting substances in blood into hepatocyte (Pu et al., 2015). Thus, they can regulate substance metabolism or gene expression (Shimizu et al., 2012).

OATP1B1 is the major transporter for statins to enter the liver. It is closely related to the occurrence of toxic and side effects, such as muscular injury (like rhabdomyolysis) in clinic (Evangeli et al., 2017). Therefore, structure, substrate/inhibitor, pharmacogenetics, and the drug-drug interaction mediated by OATP1B1 are the focuses of previous clinical studies (Wang et al., 2013). It is found recently that OATP1B3 can transport the common substrate of OATP1B1 (Suga et al., 2017). Besides, it can also transport multiple substances that do not act with OATP1B1, such as digoxin, paclitaxel and docetaxel. Moreover, OATP1B3 is the specific transport of liver under normal physiological status. However, it is highly expressed in tumor tissues and cells, like prostate cancer, colon cancer and lung cancer. OATP1B3 is not expressed in normal gastric, large intestinal and prostatic tissues (Wang et al., 2013). As a result, OATP1B3 is suggested to be accompanying with the carcinogenesis of the above organs (Pei et al., 2017).

The aim of this meta-analysis was to assess the association between SLCO1B3 gene polymorphism and prostate cancer risk.

\section{Materials and Methods}

\section{Search strategy}

PubMed, Embase, Cochrane Library, and Web of Science from inception to September 2017 were searched. Searches were conducted using combinations of keywords and free words: SLCO1B3, SLCO1B3 gene polymorphism, rs4149117 or prostate cancer.

\section{Inclusion and exclusion criteria}

The inclusion criteria were: a) randomized controlled trials, b) patients with advanced or metastatic prostate cancer, c) overall response rate, overall survival rate, recurrence-free survival.

The exclusion criteria were: a) patients started treatment before randomization, b) non-randomized controlled trials, c) candidates for watchful waiting, d) nonhuman studies and non-English studies, e) conference reports, systematic reviews or summaries, f) repeated published literature, g) studies with insufficient data integrity, systematic reviews or summaries; h) nonhuman studies and non-English studies.

\section{Coding of studies}

Three independent reviewers using a standardized form extracted relevant data from five articles. Three independent reviewers extracted first author's name, year of publication, origin country, ethnicity, cases, gene, NO (GG/TT+TG) and survival analysis. Discrepancies were discussed until reaching a consensus.

\section{Statistical analysis}

The meta-analyses was conducted using Cochrane Collaboration Software Review Manager (RevMan version 5.3). A fixed effects model, calculating risk ratio (RR) and 95\% confidence intervals (CIs) were analyzed. $P$ values less than 0.05 were considered as statistically significant. Heterogeneity studies was examined using Chi-square based Q-test in which I2 indicates level of heterogeneity. $\mathrm{I}_{2}>50 \%$ or $P_{\text {heterogeneity }}<0.1$ was high heterogeneity (Pu et al., 2017).

\section{Results}

\section{Search results and study characteristics}

A total of 1168 records were obtained from the database searching and 75 articles were available for full text and 


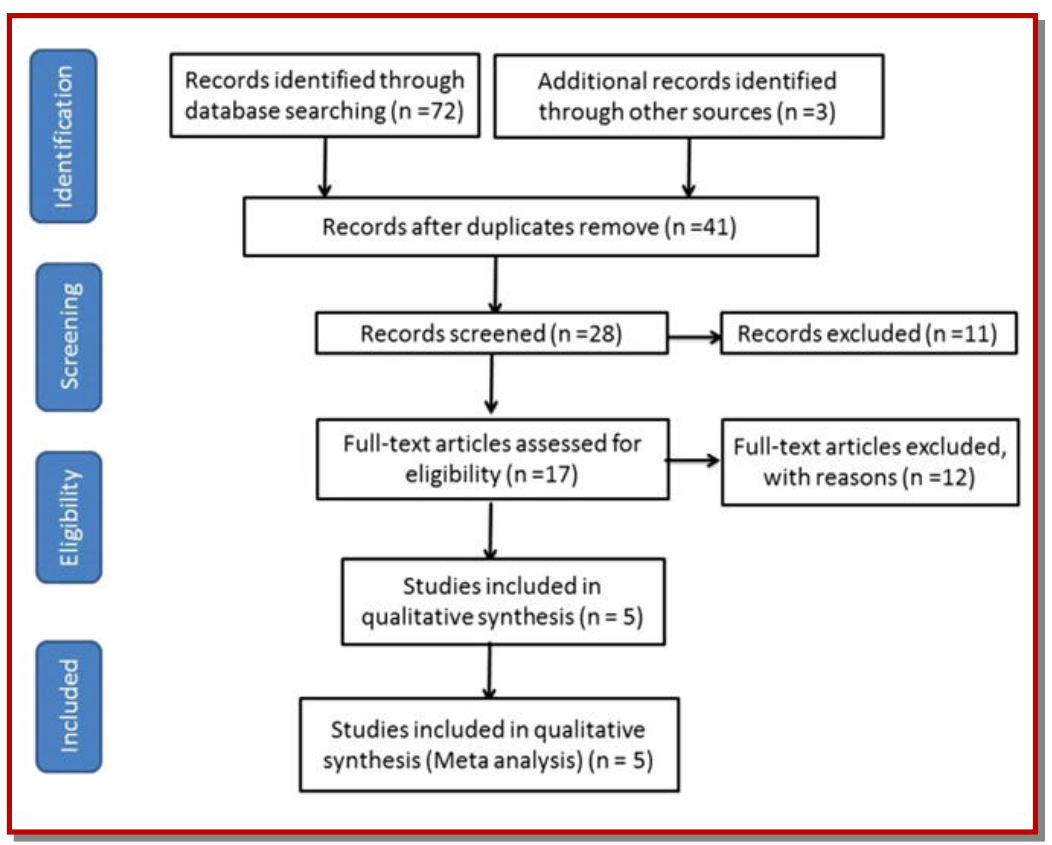

Figure 1: Search results and study characteristics

data assessment after primary screening. The number of eligible articles dropped to 41 articles through title and abstract and 5 articles (Koyama et al., 2008; Zheng et al., 2016; George et al., 2017) were selected by examining full texts of the remainder (Figure 1). The characteristics of studies were shown in Table I. 5 articles published from 2008 to 2013 with 840 patients were included in meta-analysis and were from Japan, USA and China.

Association between the mutation rate of SLCO1B3 (rs4149117) and prostate cancer risk

Five studies depicted the relationship between the mutation rate of SLCO1B3 (rs4149117) and prostate cancer risk. According to Figure 2A, the prostate cancer risk of SLCO1B3 (rs4149117, GG) was markedly higher than that of SLCO1B3 (rs4149117, TT/TG) (RR=0.44, 95\% CI: 0.39-0.49, p<0.00001). Meanwhile, the prostate cancer risk of SLCO1B3 (rs4149117, GG) was also markedly higher than that of SLCO1B3 (rs4149117, TT)
$(R R=0.37,95 \%$ CI: 0.32-0.42, $p<0.00001$, Figure 2B). The prostate cancer risk of SLCO1B3 (rs4149117, GG) was also markedly higher than that of SLCO1B3 (rs4149117, TG) $(\mathrm{RR}=0.07,95 \% \mathrm{CI}$ : 0.05-0.10, $\mathrm{p}<0.00001$, Figure 2C). These results showed that the mutation rate of SLCO1B3 (rs4149117) is GG in prostate cancer patient.

Association between the mutation rate of SLCO1B3 (rs4149117) and recurrence-free survival (C) of prostate cancer

Three studies depicted the relationship between SLCO1B3 (rs4149117) and recurrence-free survival (RFS) of prostate cancer. According to Figure 3A, 2 years RFS of prostate cancer patient with SLCO1B3 (rs4149117, GG) was markedly higher than that of SLCO1B3 (rs4149117, TT/TG) (RR=0.59, 95\% CI: 0.41$0.85, \mathrm{p}=0.005)$. Meanwhile, 5 years RFS of prostate cancer patient with SLCO1B3 (rs4149117, GG) was higher than that of SLCO1B3 (rs4149117, TT/TG) (RR=

\begin{tabular}{|c|c|c|c|c|c|c|c|c|}
\hline \multicolumn{9}{|c|}{ Table I } \\
\hline \multicolumn{9}{|c|}{ Basic characteristics of included studies } \\
\hline Study & Reference & Year & Country & Ethnicity & Cases & Gene & $\begin{array}{c}\mathrm{NO} \\
(\mathrm{GG} / \mathrm{TT}+\mathrm{TG})\end{array}$ & $\begin{array}{l}\text { Survival } \\
\text { analysis }\end{array}$ \\
\hline Fujimoto & (Koyama et al., 2008) & 2013 & Japan & Asian & 87 & rs4149117 & $49 / 38$ & RFS \\
\hline Sharifi & (Zheng et al., 2016) & 2008 & USA & Caucasian & 136 & rs4149117 & $100 / 36$ & RFS \\
\hline Hamada & (Koyama et al., 2008) & 2008 & USA & Caucasian & 58 & rs4149117 & $49 / 9$ & RFS \\
\hline Pressler & (George et al., 2017) & 2011 & USA & Caucasian & 21 & rs4149117 & $13 / 8$ & RFS \\
\hline Yang & (Koyama et al., 2008) & 2011 & China & Asian & 538 & rs4149117 & $368 / 162$ & RFS \\
\hline
\end{tabular}




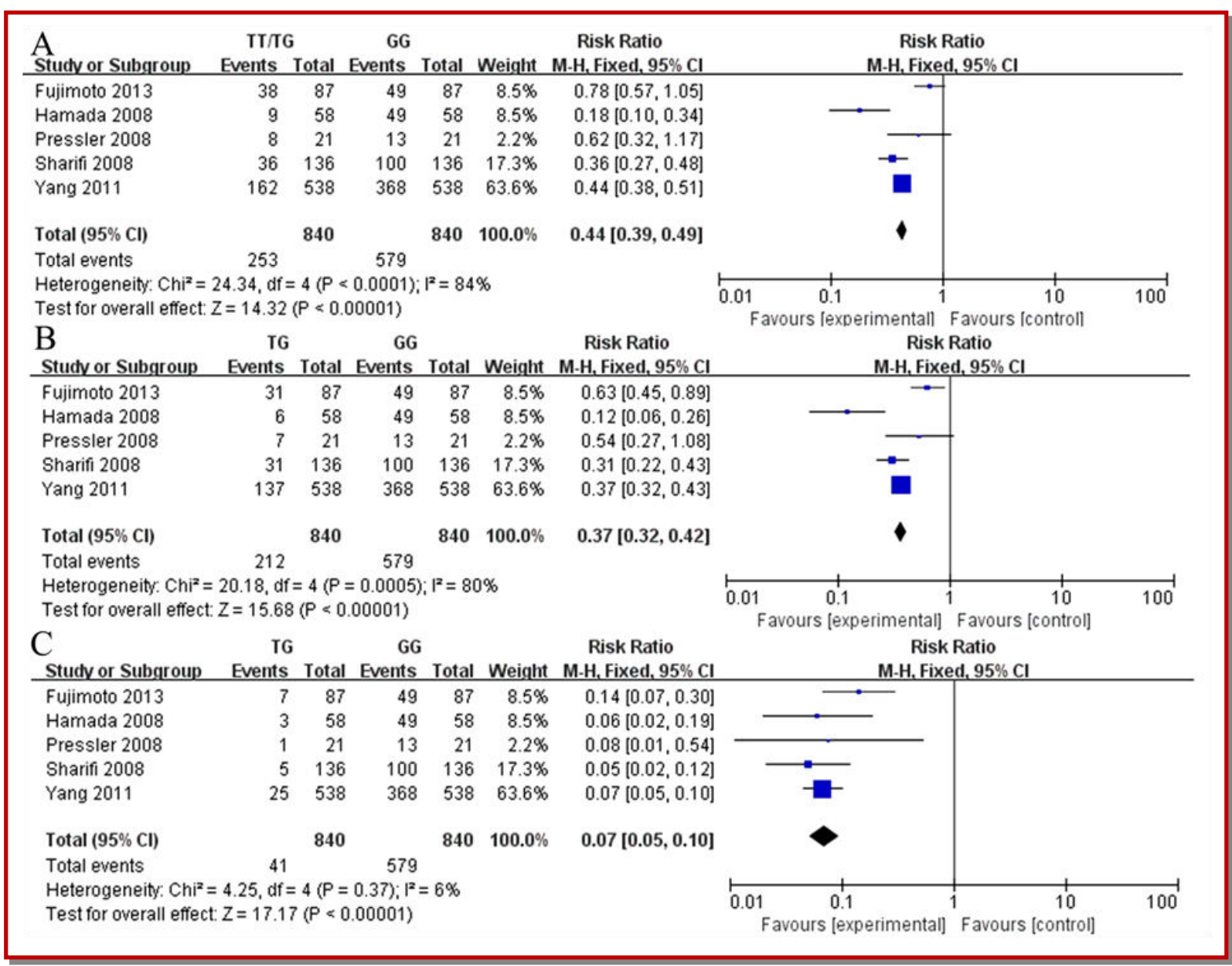

Figure 2: Association between the mutation rate of SLCO1B3 (rs4149117) and prostate cancer risk TT/TG vs GG (A), TT vs GG (B), TG vs GG (C); TT, rs4149117 TT; TG, rs4149117 TG; GG, 4149117 GG

\begin{tabular}{|c|c|c|c|c|c|c|c|c|c|}
\hline \multicolumn{10}{|c|}{ Table II } \\
\hline \multicolumn{10}{|c|}{ Pooled HRs and 95\% CIs in meta-analysis } \\
\hline Variable & Ref. & $\begin{array}{l}\text { No. of } \\
\text { studies }\end{array}$ & $\begin{array}{c}\text { No. of } \\
\text { patients }\end{array}$ & HR & $95 \% \mathrm{CI}$ & $\mathrm{p}$ & $\begin{array}{l}\text { Effects } \\
\text { model }\end{array}$ & \multicolumn{2}{|c|}{$\begin{array}{l}\text { Heterogeneity } \\
\mathrm{I}^{2}(\%) \mathrm{P}_{\mathrm{h}}\end{array}$} \\
\hline \multicolumn{10}{|l|}{ Mutation rate } \\
\hline TT/TG vs GG & & 5 & 840 & 0.4 & $0.4-0.5$ & $<0.00001$ & \multirow[t]{7}{*}{ Fixed } & 84 & $<0.001$ \\
\hline TT vs GG & & 5 & 840 & 0.4 & $0.3-0.4$ & $<0.00001$ & & 80 & 0.0005 \\
\hline TG vs GG & & 5 & 840 & 0.1 & $0.1-0.1$ & $<0.00001$ & & 6 & 0.37 \\
\hline RFS & & & & & & & & & \\
\hline 2 years & & 3 & 281 & 0.6 & $0.4-0.9$ & 0.005 & & 90 & $<0.0001$ \\
\hline 5 years & & 3 & 281 & 0.6 & $0.3-1.1$ & 0.10 & & 0 & 0.40 \\
\hline 10 years & & 2 & 145 & 0.7 & $0.3-1.6$ & 0.36 & & 0 & 0.36 \\
\hline
\end{tabular}

0.61, 95\% CI: 0.34-1.09, p= 0.10, Figure 3B), without statistically significant change. However, There was no evidence of existed significant statistical relationship between SLCO1B3 (rs4149117) and 10 years RFS of prostate cancer $(\mathrm{RR}=0.67,95 \% \mathrm{CI}: 0.28-1.59, \mathrm{p}=0.36$, Figure $3 \mathrm{C}$ ). These results showed that SLCO1B3 (rs4149117, GG) enhanced RFS of prostate cancer.

\section{Publication bias}

Funnel plots for this meta-analysis of association between SLCO1B3 gene polymorphism (rs4149117) and prostate cancer risk. According to Figure 4, and Table II, 


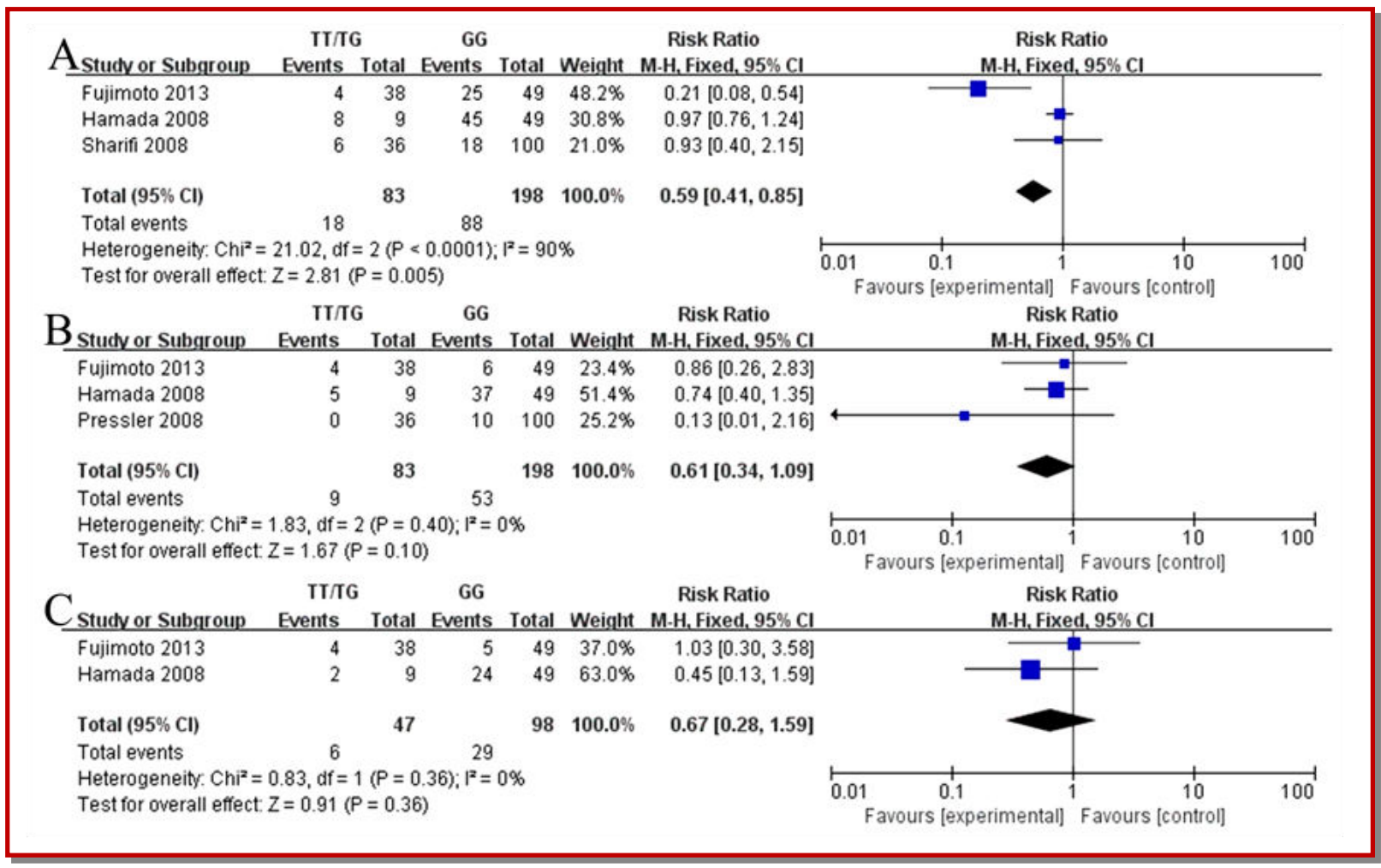

Figure 3: Association between the mutation rate of SLCO1B3 (rs4149117) and recurrence-free survival of prostate cancer 2 years RFS (A), 5 years RFS (B), and 10 years RFS (C) of prostate cancer

TT, rs4149117 TT; TG, rs4149117 TG; GG, 4149117 GG

the funnel plots for six indexes were symmetric, indicating no obvious publication bias. Furthermore, there were associations between TT/TG vs GG ( $\mathrm{I}^{2}=$ $\left.84 \%, P_{\text {heterogeneity }}<0.001\right)$, TT vs GG $\left(\mathrm{I}^{2}=80 \%, P_{\text {heterogeneity }}=\right.$ $0.0005)$, TG vs GG (I $\left.2=6 \%, P_{\text {heterogeneity }}=0.37\right), 2$ years RFS (I $\left.2=90 \%, P_{\text {heterogeneity }}<0.0001\right), 5$ years RFS CG $\left(\mathrm{I}^{2}=\right.$ $\left.0 \%, P_{\text {heterogeneity }}=0.40\right)$ and 10 years RFS $\left(\mathrm{I}^{2}=0 \%\right.$, $\left.P_{\text {heterogeneity }}=0.36\right)($ Table II).

\section{Discussion}

Prostate cancer is the most common male malignancy in Urology. In addition, it is the second killer inducing tumor-related death in male (Medioni et al., 2014). In USA, the morbidity of prostate cancer has overpassed that of lung cancer. It has become the male malignancy with the highest morbidity (Montgomery et al., 2016). Research has found that prostate cancer morbidity shows obvious geographical difference (Montgomery et al., 2016). According to statistics, Austria, Caribbean Sea and Scandinavian area have the highest morbidity (Medioni et al., 2014). In contrast, Asian area and North African area have the lowest morbidity. Prostate cancer morbidity in Asia is far lower than that in European and American countries. However, it displays an increasing trend in recent years, with more markedly increasing amplitude than developed European and
American countries (Montgomery et al., 2016). Research has indicated that the national life and dietary modes in China have been gradually westernized. Prostate cancer patients consulted in Urology in China, especially in developed areas, are growing (Vasarainen et al., 2013). It is predicted that the morbidity and mortality of prostate cancer in Chinese men will greatly rise within the coming 20 years. Moreover, the incidence cases and death cases will increase by 2030. Meanwhile, it is estimated that prostate cancer morbidity in future 5 years is probably to exceed that of bladder cancer (Montgomery et al., 2016). Thereby, it will become the urogenital system tumor with the highest morbidity in Chinese men. Therefore, the issue of prostate cancer that China faces in the future is non-negligible. This meta-analysis showed that the prostate cancer risk of SLCO1B3 (rs4149117, GG) was markedly higher than that of SLCO1B3 (rs4149117, TT/TG, RR=0.44, 95\% CI: $0.39-0.49, \mathrm{p}<0.00001)$, rs4149117 (TT, RR=0.37, 95\% CI: $0.32-0.42, \mathrm{p}<0.00001)$ and $\mathrm{rs} 4149117$ (TG, $\mathrm{RR}=0.07,95 \%$ CI: $0.05-0.10, \mathrm{p}<0.00001)$. These results showed that the mutation rate of SLCO1B3 (rs4149117) is GG in prostate cancer patient.

OATP1B3 belongs to the solute transporter superfamily. It is mainly responsible for transporting endogenous and exogenous substances to hepatocyte for metabolism (Ayalasomayajula et al., 2016). OATP1B3 is 

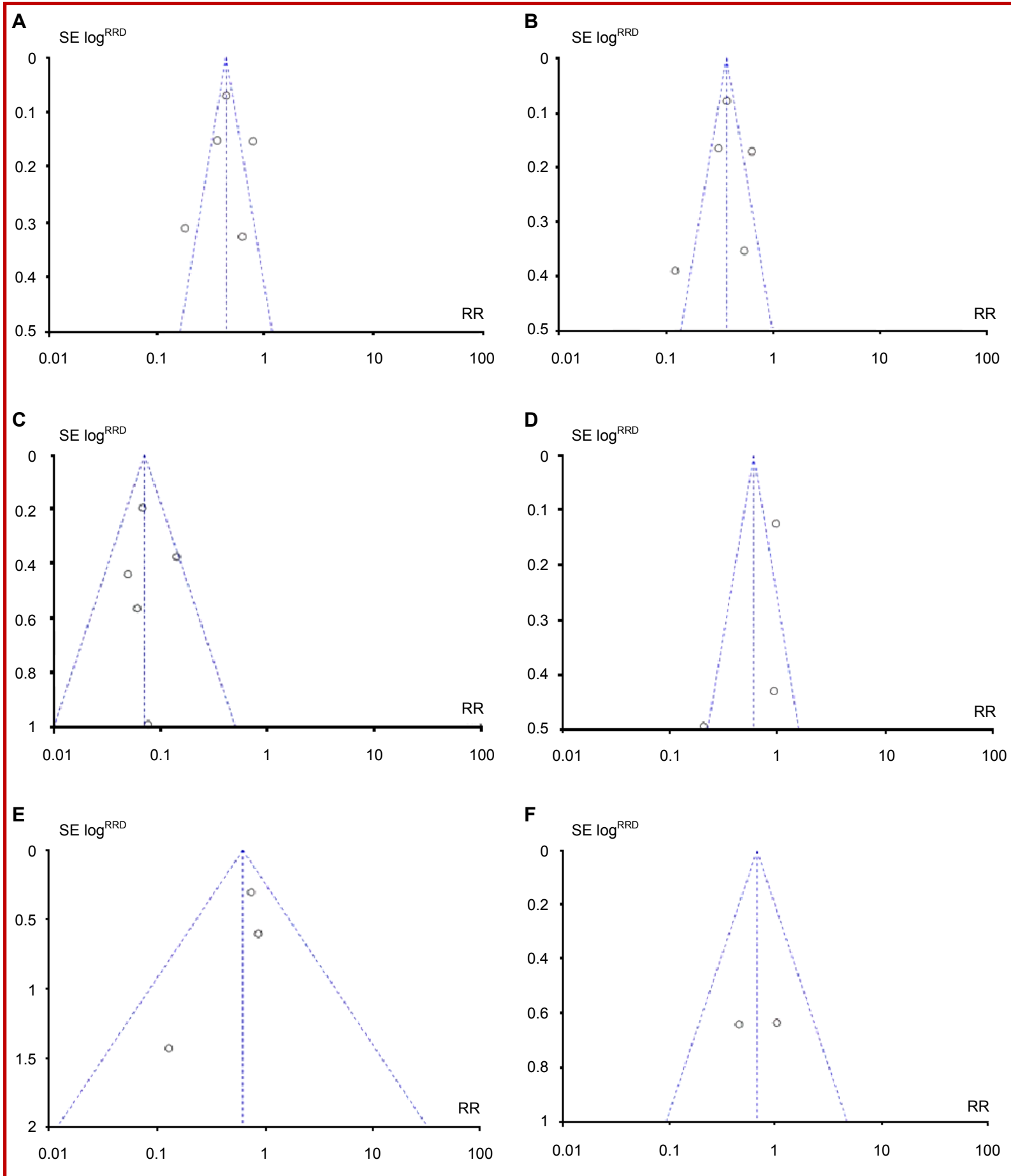

Figure 4: Publication bias

TT/ TG vs GG (A), TT vs GG (B), TG vs GG (C), 2 years RFS (D), 5 years RFS (E), and 10 years RFS (F) of prostate cancer

a liver-specific transporter (de Morree et al., 2016). It is generally localized in liver cell membrane in sinusoid side (Bedewy and El-Maghraby, 2013). It is found in recent studies that, high OATP1B3 expression exists in tumor tissues and cells like prostate cancer, colon cancer and lung cancer. SLCO1B3 shows obvious gene polymorphism (de Morree et al., 2016). Notably, $334 \mathrm{~T}>\mathrm{G}$ and $699 \mathrm{G}>\mathrm{A}$ haplotypes can markedly affect the transport activity of OATP1B3 (Bedewy and ElMaghraby, 2013; Suga et al., 2017). Therefore, they can mediate drug-drug interaction and result in individual difference in clinical medication. Our study showed 
that 2 years RFS of prostate cancer patient with SLCO1B3 (rs4149117, GG) was markedly higher than that of SLCO1B3 (rs4149117, TT/TG) (RR=0.59, 95\% CI: $0.41-0.85, p=0.005)$. These results showed that SLCO1B3 (rs4149117, GG) enhanced RFS of prostate cancer, however, we also found that mutation rate of SLCO1B3 (rs4149117) is GG in prostate cancer patient. These showed that SLCO1B3 (rs4149117, GG) is common genotype, SLCO1B3 (rs4149117, TT/TG) induced prostate cancer and inhibited RFS in patient with prostate cancer. In further study, we will analyze the mutation rate of SLCO1B3 (rs4149117) of normal healthy volunteers and patient with prostate cancer.

There are several limitations to our study. First, the numbers of articles were relatively small. Second, there were differences in the numbers of participants in the five articles comparisons among the interventions, which may have impacted the results. Lastly, all articles reported RFS of prostate cancer patient that is too singleness.

\section{Conclusion}

Based on our results, we concluded that SLCO1B3 (rs4149117, GG) enhanced RFS of prostate cancer patients.

\section{Conflict of Interest}

The authors have no collisions of interest to disclose.

\section{References}

Ayalasomayajula S, Han Y, Langenickel T, Malcolm K, Zhou W, Hanna I, Alexander N, Natrillo A, Goswami B, Hinder M, Sunkara G. In vitro and clinical evaluation of OATPmediated drug interaction potential of sacubitril/valsartan (LCZ696). J Clin Pharm Ther. 2016; 41: 424-31.

Bedewy AM, El-Maghraby SM. Do SLCO1B3 (T334G) and CYP3A5*3 polymorphisms affect response in Egyptian chronic myeloid leukemia patients receiving imatinib therapy? Hematology 2013; 18: 211-16.

Ben-Josef AM, Chen J, Wileyto P, Doucette A, Bekelman J, Christodouleas J, Deville C, Vapiwala N. Effect of eischens yoga during radiation therapy on prostate cancer patient symptoms and quality of life: A randomized phase II trial. Int J Radiat Oncol Biol Phys. 2017; 98: 1036-44.

de Morree ES, Bottcher R, van Soest RJ, Aghai A, de Ridder CM, Gibson AA, Mathijssen RH, Burger H, Wiemer EA, Sparreboom A, de Wit R, van Weerden WM. Loss of SLCO1B3 drives taxane resistance in prostate cancer. Br J Cancer. 2016; 115: 674-81.

Evangeli L, Ioannis S, Valentinos K, Antigony M, Elli I, Eleftheria H, Vasiliki G, Evangelos B. SLCO1B3 screening in colorectal cancer patients using High-Resolution Melting
Analysis method and immunohistochemistry. Tumour Biol. 2017; 39: 1010428317691176.

George S, Miao D, Demetri GD, Adeegbe D, Rodig SJ, Shukla S, Lipschitz M, Amin-Mansour A, Raut CP, Carter SL, Hammerman P, Freeman GJ, Wu CJ, Ott PA, Wong KK, Van Allen EM. Loss of PTEN is associated with resistance to antiPD-1 checkpoint blockade therapy in metastatic uterine leiomyosarcoma. Immunity 2017; 46: 197-204.

Hieronymus H, Schultz N, Gopalan A, Carver BS, Chang MT, Xiao Y, Heguy A, Huberman K, Bernstein M, Assel M, Murali R, Vickers A, Scardino PT, Sander C, Reuter V, Taylor BS, Sawyers CL. Copy number alteration burden predicts prostate cancer relapse. Proc Natl Acad Sci USA. 2014; 111: 11139-44.

Koyama K, Kagamu H, Miura S, Hiura T, Miyabayashi T, Itoh R, Kuriyama H, Tanaka H, Tanaka J, Yoshizawa H, Nakata K, Gejyo F. Reciprocal CD4+ T-cell balance of effector CD62Llow CD4+ and CD62LhighCD25+ CD4+ regulatory $\mathrm{T}$ cells in small cell lung cancer reflects disease stage. Clin Cancer Res. 2008; 14: 6770-79.

Medioni J, Deplanque G, Ferrero JM, Maurina T, Rodier JM, Raymond E, Allyon J, Maruani G, Houillier P, Mackenzie S, Renaux S, Dufour-Lamartinie JF, Elaidi R, Lerest C, Oudard $\mathrm{S}$. Phase I safety and pharmacodynamic of inecalcitol, a novel VDR agonist with docetaxel in metastatic castrationresistant prostate cancer patients. Clin Cancer Res. 2014; 20: 4471-77.

Montgomery B, Eisenberger MA, Rettig MB, Chu F, Pili R, Stephenson JJ, Vogelzang NJ, Koletsky AJ, Nordquist LT, Edenfield WJ, Mamlouk K, Ferrante KJ, Taplin ME. Androgen Receptor Modulation Optimized for Response (ARMOR) phase I and II studies: Galeterone for the treatment of castration-resistant prostate cancer. Clin Cancer Res. 2016; 22: 1356-63.

Obara W, Sato F, Takeda K, Kato R, Kato Y, Kanehira M, Takata R, Mimata H, Sugai T, Nakamura Y, Fujioka T. Phase I clinical trial of cell division associated 1 (CDCA1) peptide vaccination for castration resistant prostate cancer. Cancer Sci. 2017; 108: 1452-57.

Pei Q, Yang L, Tan HY, Liu SK, Liu Y, Huang L, Li RH, Wan Q, Huang J, Guo CX, Zuo XC, Li J, Yang GP. Effects of genetic variants in UGT1A1, SLCO1B3, ABCB1, ABCC2, ABCG2, ORM1 on PK/PD of telmisartan in Chinese patients with mild to moderate essential hypertension. Int J Clin Pharmacol Ther. 2017; 55: 659-65.

Petrioli R, Roviello G, Fiaschi AI, Laera L, Miano ST, De Rubertis G, Barbanti G, Bianco V, Brozzetti S, Francini E. Rechallenge of docetaxel combined with epirubicin given on a weekly schedule in advanced castration-resistant prostate cancer patients previously exposed to docetaxel and abiraterone acetate: A single-institution experience. Med Oncol. 2015; 32: 52.

Pu Z, Wang Q, Xie H, Wang G, Hao H. Clinical, pathological and prognostic significance of survivin expression in renal cell carcinoma: A meta-analysis. Oncotarget 2017; 8: 1982533.

$\mathrm{Pu} \mathrm{Z,} \mathrm{Zhang} \mathrm{X,} \mathrm{Chen} \mathrm{Q,} \mathrm{Yuan} \mathrm{X,} \mathrm{Xie} \mathrm{H.} \mathrm{Establishment} \mathrm{of} \mathrm{an}$ expression platform of OATP1B1 388GG and 521CC genetic polymorphism and the therapeutic effect of tamoxifen in 
MCF-7 cells. Oncol Rep. 2015; 33: 2420-28.

Shimizu K, Takashima T, Yamane T, Sasaki M, Kageyama H, Hashizume Y, Maeda K, Sugiyama Y, Watanabe Y, Senda M. Whole-body distribution and radiation dosimetry of [11C] telmisartan as a biomarker for hepatic organic anion transporting polypeptide (OATP) 1B3. Nucl Med Biol. 2012; 39: 847-53.

Suga T, Yamaguchi H, Sato T, Maekawa M, Goto J, Mano N. Preference of conjugated bile acids over unconjugated bile acids as substrates for OATP1B1 and OATP1B3. PLoS ONE. 2017; 12: e0169719.

Vasarainen H, Lahdensuo K, Savolainen R, Ruutu M, Taari K, Rannikko A. Diffusion-weighted magnetic resonance imaging in prostate cancer patients on active surveillance one year after diagnosis and before repeat biopsy. Scand J Urol. 2013; 47: 456-61.
Wang Z, Qu L, Yao J, Yang X, Li G, Zhang Y, Li J, Wang X, Bai J, Xu G, Deng X, Yang N, Wu C. An EAV-HP insertion in 5' Flanking region of SLCO1B3 causes blue eggshell in the chicken. PLoS Genet. 2013; 9: e1003183.

Zheng H, Liu X, Zhang J, Rice SJ, Wagman M, Kong Y, Zhu L, Zhu J, Joshi M, Belani CP. Expression of PD-1 on CD4+ T cells in peripheral blood associates with poor clinical outcome in non-small cell lung cancer. Oncotarget 2016; 7: 56233-40.

Zhou T, Zeng SX, Ye DW, Wei Q, Zhang X, Huang YR, Ye ZQ, Yang Y, Zhang W, Tian Y, Zhou FJ, Jie J, Chen SP, Sun Y, Xie LP, Yao X, Na YQ, Sun YH. A multicenter, randomized clinical trial comparing the three-weekly docetaxel regimen plus prednisone versus mitoxantone plus prednisone for Chinese patients with metastatic castration refractory prostate cancer. PLoS ONE. 2015; 10: e0117002. 